\title{
Neo-Aristotelian Naturalism and the Evolutionary Objection: Rethinking the Relevance of Empirical Science
}

\author{
Parisa Moosavi
}

\begin{abstract}
Neo-Aristotelian ethical naturalism is a modern attempt to place morality in the natural world using ideas from Aristotle's teleological metaphysics. Proponents of this view argue that moral virtue in human beings is an instance of natural goodness, a kind of goodness supposedly also found in the realm of non-human living things. Many critics question whether neo-Aristotelian naturalism is tenable in light of modern evolutionary biology. Two influential lines of objection have appealed to an evolutionary understanding of human nature and natural teleology to argue against this view. In this paper, I offer a reconstruction of these two seemingly different lines of objection as raising instances of the same dilemma, giving neo-Aristotelians a choice between contradicting our considered moral judgment and abandoning metaethical naturalism. I argue that resolving the dilemma requires showing a particular kind of continuity between the norms of moral virtue and norms that are necessary for understanding non-human living things. I also argue that in order to show such a continuity, neo-Aristotelians need to revise the relationship they adopt with empirical science and acknowledge that the latter is relevant to assessing their central commitments regarding living things. Finally, I argue that to move this debate forward, both neo-Aristotelians and their critics should pay attention to recent work on the concept of organism in evolutionary and developmental biology.
\end{abstract}

\section{Introduction}

As a modern attempt to give a naturalist account of ethics using ideas from Aristotle's teleological metaphysics, neo-Aristotelian naturalism has received a lot of critical attention. Proponents of this view, most notably Philippa Foot and Rosalind Hursthouse, argue for a continuity between the moral and the natural realm. Their central claim is that moral goodness is an instance of what they call natural goodness, a kind of goodness supposedly also found in nature in the biological realm of plants and non-human animals. They argue that the goodness of moral virtue in humans is akin to the goodness of deep roots in an oak tree. In both cases what is good enables the kind of organism in question to flourish.

A paradigmatic account of natural goodness is given by Philippa Foot (2001). Foot describes evaluations of natural goodness as a kind of evaluation that applies to living things and their parts 
and characteristics. These are evaluations that we make when we say, for instance, that sturdy and deep roots are good in an oak, or pliability is good in a reed. Foot's account of these evaluations relies on Michael Thompson's work on representation of life.

According to Thompson (2008), there is a distinctive form of thought that applies to the domain of life and can underwrite evaluations of natural goodness and defect. This form of thought is manifested in the kind of generic statement that we typically encounter in a nature documentary or a field guide - statements such as 'bobcats breed in the spring' and 'oak trees have deep and sturdy roots'. Thompson calls these natural-historical judgments, and argues that they articulate the characteristic features and activities of the form of life, or the life-form, to which individual living things belong. On his account, these judgments have a distinctive form of generality that is distinct from other forms such as universal or statistical generality. Natural-historical judgments can be true despite having exceptions or instances that do not match the general description expressed in them. For example, the first natural-historical judgment above can be true despite there being bobcats that don't breed in the spring. Moreover, what we can infer from such exceptions is that there is something wrong with the nonconforming instances. This is how naturalhistorical judgments underwrite evaluative inferences to natural goodness and defect. We can say, for instance, that bobcats that don't breed in the spring are naturally defective and the ones that do are, to that extent, naturally good. According to Thompson, for any given life-form $S$, the system of natural-historical judgments that have $S$ as their subject articulates the natural history, or the characteristic life, of that kind of organism. This natural history then sets the standard for making evaluations of natural goodness and defect.

Foot adds a teleological dimension to Thompson's account by arguing that the relevant generic judgments are those concerning what "plays a part" in the characteristic life of a kind of organism. Take, for instance, the two judgments 'the male peacock has a brightly-colored tail' and 'the blue tit has a blue patch on its head'. These judgments are superficially similar, but only the former underwrites inference to goodness and defect. This is because a male peacock's brightly-coloured tail plays a part in the characteristic life of the bird by attracting mates in a way that a blue tit's having a blue patch on its head does not (2001: 30). Evaluations of natural goodness thus evaluate aspects of an organism based on their function in enabling the organism to flourish, i.e., to exemplify the characteristic life cycle of its life-form. For plants and non-human animals, the life cycle roughly consists of self-maintenance and reproduction. But each form of life has its own 
characteristic way of achieving these ends, which determines the norms of natural goodness for the bearers of that life-form.

The aim of the neo-Aristotelian project is to extend evaluations of natural goodness to the case of human beings and to show that our judgments of goodness and badness in humans-including our judgments of moral evaluation - instantiate the same type of evaluation. Moral evaluations in particular concern goodness of the will. But goodness of the will is seen as an instance of natural goodness along with goodness of other human faculties like sight and memory. Practical rationality is not viewed as an abstract idea applicable to persons or rational beings as such. It is rather understood as an instance of natural goodness in the specifically human form of life, which is to say that it is tied to the conditions and characteristics of human life in a manner comparable to the norms for evaluating human sight and memory.

Critics have responded to the neo-Aristotelian project with a great deal of skepticism. Aristotle had an essentialist, teleological conception of nature that does not seem tenable in light of modern science. The neo-Aristotelian account of nature is similarly teleological when it comes to living things, and seems equally out of touch with modern biology. Many critics thus appeal to empirical sciences and particularly evolutionary biology to argue against neo-Aristotelian naturalism. The discussion surrounding these objections, however, lacks clarity and agreement about their exact import. As I argue below, the way these objections are usually interpreted obscures the relation between two influential versions of the evolutionary objection that should be discussed together. One of my aims in this paper is to highlight this relation, and articulate what I take to be the strongest interpretation of the evolutionary objection, i.e., a dilemma ultimately targeting the neoAristotelians' claim to naturalism.

Foot presents her view as "a naturalistic theory of ethics" (2001: 5) and contrasts it with Moore's non-naturalism, various forms of non-cognitivism, and Kantianism. Rosalind Hursthouse similarly characterizes her account of virtue as a form of ethical naturalism. She explicitly points out that while as an Aristotelian she aims to base ethics in considerations of human nature, it is crucial to her account that human beings are understood as "part of the natural, biological order of living things" (1999: 205). ${ }^{1}$ Yet, neither Foot nor Hursthouse consult scientific findings in delineating their account of natural goodness or human nature. In fact, they intentionally steer clear

\footnotetext{
${ }^{1}$ She says, for instance, that if humans are understood as creatures with an immortal soul or as persons or rational agents, it will not be clear that they are a natural kind of thing.
} 
of scientific accounts, which is particularly puzzling in light of their promise of offering a naturalist view.

I argue that it is the neo-Aristotelians' commitment to naturalism that has invited objections based on evolutionary biology and empirical science. In response to these objections, neoAristotelians rightly point out that the conception of human nature that is central to their view is not reducible to an evolutionary account of the human species (see, e.g., Hacker-Wright 2009: 315-317). But the question remains what renders their conception of human nature naturalistic? As I will argue below, although neo-Aristotelians are right that naturalism does not require adopting a conception of human nature that comes from biology, it does require showing a continuity between the human domain and a domain that is best investigated via biological science. Thus, neo-Aristotelians cannot offer an adequate response to the evolutionary objection without acknowledging that empirical science is relevant to assessing some of their central commitments regarding living things.

I also argue that the way most critics appeal to empirical science and the picture they draw of evolutionary biology involves assumptions that have been seriously challenged in last twenty years. Recent work in philosophy of biology on the concept of an organism and its place in evolutionary and developmental biology has been overlooked by neo-Aristotelians and their critics alike. I argue that this ongoing conversation in philosophy of biology is relevant to assessing the evolutionary objection and can help move the debate forward.

\section{An Evolutionary-Inspired Dilemma}

Exploring the critical literature on neo-Aristotelian naturalism, we can recognize two lines of objection that appeal to evolutionary biology or some other branch of empirical science. The first line of objection appeals to an evolutionary understanding of human nature to question whether substantial virtues like justice and benevolence are instances of natural goodness in human beings (see Millgram 2009, Andreou 2006, and Woodcock 2006). The second line of objection appeals to an evolutionary account of the concept of biological function to undermine the 'flourishingbased' concept of function that underlies the neo-Aristotelian concept of natural goodness (see Fitzpatrick 2000). Most critics only focus on one of these objections, and neo-Aristotelians in their responses deal with them separately. But I will argue that these objections share a basic structure and ultimately raise the same problem - a problem that is best understood as a dilemma. 
The dilemma can be articulated by identifying two desiderata for the neo-Aristotelian project of offering a naturalist account of ethics. The central claim of Neo-Aristotelian naturalism is that moral virtue is an instance of natural goodness in human beings, where natural goodness is a sort of goodness found in nature among living things. There are two parts to this claim that are both essential for the project to succeed: that moral virtue is an instance of what they call 'natural goodness' in humans, and that the latter is in fact part of the natural world. Thus, we can interpret neo-Aristotelian naturalism as offering the following argument for ethical naturalism.

\section{Simple Argument for Naturalism:}

1. Norms of natural goodness are natural. (Naturalness)

2. Norms of moral goodness are instances of norms of natural goodness in human beings. (Normative Adequacy)

C. Therefore, norms of moral goodness are natural.

Once we understand the neo-Aristotelian project in this way, it becomes apparent that there is a tension between the two premises of the argument. Natural goodness should be defined such that norms of natural goodness are natural norms, but also such that they coincide with norms of moral goodness in the human case. Each of these requirements pulls in a different direction. Let's call the first one the premise of Naturalness and the second one the premise of Normative Adequacy. Even without a full grasp on what it takes to secure each of these premises, we can see that they are difficult to secure at the same time. A straightforward way to ensure Naturalness would be to define natural goodness in terms of biological function or adaptiveness in a strictly evolutionary sense, since evolutionary function is uncontroversially an aspect of the natural world. But it would be hard to expect such evolutionary norms to coincide with our considered judgment about moral virtue and fulfill Normative Adequacy. On the other hand, an easy way to ensure Normative Adequacy would be to stipulate norms of natural goodness such that they coincide with our considered judgment about moral norms. But then it would be far from clear that such stipulated norms meet the requirement of Naturalness. Thus, neo-Aristotelians seem to be facing a difficult choice between abandoning ethical naturalism and contradicting our considered moral judgment. This is how the tension between the two desiderata of neo-Aristotelian naturalism seems to give rise to a dilemma. 
Although the two lines of evolutionary objection in the literature are not usually presented in this way, I suggest that they both raise instances of this dilemma. The first objection, which is often called the Pollyanna Problem, focuses on natural goodness in human beings. Milgram (2009), Andreou (2006), and other critics who raise this objection appeal to a scientific understanding of human nature to argue that it is naively optimistic or 'Polyannish' to assume that the extension of natural goodness in humans coincides with our considered judgment about moral virtue. The second objection does not share this focus on human beings but has a similar structure. It relies on an understanding of natural goodness in terms of evolutionary functions to question whether the extension of natural goodness in general coincides with our considered judgment about a living thing's flourishing. Fitzpatrick (2000) who raises this objection primarily focuses on natural goodness in non-humans. Since his argument appeals to Richard Dawkins' account of evolution in The Selfish Gene (1976), I will call the problem he raises the Selfish Gene Problem.

Despite the similar structure of the two objections, they are often seen as posing very different questions (see, e.g., how they are treated separately in Lott 2012a and 2012b). The Pollyanna Problem is interpreted as granting the neo-Aristotelian account of natural goodness and only questioning the attempt to show that moral goodness is an instance of natural goodness. The Selfish Gene Problem, on the other hand, is interpreted as questioning the neo-Aristotelian account of natural goodness in its own right. In the following sections, I argue that both of these characterizations are inaccurate. The Pollyanna Problem cannot be interpreted as granting the neoAristotelian account of natural goodness, because the critics' apparent misrepresentation of the neo-Aristotelian account has to be seen in the context of their attempt to start from a properly naturalist account of natural goodness. Nor can the Selfish Gene criticism of natural goodness be understood apart from the supposed relation of natural goodness to moral goodness. Instead, both objections are instances of the dilemma articulated above. They start from a scientifically respectable interpretation of natural goodness to raise problems having to do with normative adequacy. And although they raise the problem at different levels, what is ultimately at issue in both cases is the tension between the two premises in the neo-Aristotelians' argument for ethical naturalism. 


\section{The Pollyanna Problem}

Millgram (2009), Andreou (2006), Woodcock (2006), and Odenbaugh (2015) raise the Pollyanna Problem, which concerns evaluations of natural goodness in human beings. These critics appeal to evolutionary psychology or other empirical sciences for insight into what would be naturally goodn in the life of humans, and then point to the objectionable implications of understanding morality in those terms as a redutio of neo-Aristotelian naturalism.

What happens if we consult a scientific understanding of human nature and try to derive moral virtues from such an understanding? Critics give many examples of problematic results that could follow. Instead of virtues like justice and benevolence, morally objectionable traits like infanticide, rape, and xenophobia may turn out to belong in the life of the human species. Millgram (2009: 561-562) cites empirical research suggesting that "humans value occupying dominant positions in hierarchies to a degree not compatible with justice of any kind", or that "human males are finetuned by natural selection to rape women in a suitable range of circumstances". Andreou (2006) similarly argues that sociobiologists seek and find plausible survival-and-reproduction-related functions not only for "nice" phenomena, like maternal love, but also for "nasty" phenomena like sex-selective infanticide by mothers. Woodcock (2006) adds that models of human cooperation reveal that altruistic behavior in humans only exists within significant limits and with considerable side effects. He claims that the most effective mechanisms to prevent free-riders from invading groups of altruists involve xenophobic dispositions and forms of prejudice against people outside one's interacting group, which are morally objectionable. ${ }^{2}$

In short, the objection is that given what evolutionary science tells us about human nature, natural goodness in humans does not coincide with our considered judgment about moral virtue. Neo-Aristotelian naturalism thus seems to offer a naturalist account of moral virtue only at the expense of a significant revision of our substantial conception of virtue - a revision that neither neo-Aristotelians nor their opponents are willing to embrace. To put this in terms of an objection to the Simple Argument for Naturalism, the idea is that understanding natural goodness in terms of evolutionary adaptiveness secures Naturalism, but empirical research suggests that it fails at Normative Adequasy.

\footnotetext{
2 The empirical research cited by these authors includes Frank 1985; Thornhill and Palmer 200o; Hrdy 1999; Hirshleifer and Rasmusen 1989; and Wilson and Dugatkin 1997.
} 
One could respond to this objection by questioning the validity of the empirical research cited by critics. Does evolutionary psychology really show rape and infanticide to be adaptive for human beings? Some of the empirical claims made above are in fact called into question by scholars from various disciplines (see Lloyd 2001; Travis 2003; Kitcher and Vickers 2003). However, this line of response is not fully effective. Even if the cited research fails to show human nature to be at odds with virtues like justice and benevolence, it seems extremely unlikely that better empirical research would deliver results that are in line with our considered moral judgment. Note that our considered moral judgment is formed independently of this kind of empirical research. In fact, the mere possibility that scientific findings could refute our conception of virtue seems implausible. As Thompson says, consulting a "biologistic" conception of human nature would be to give "a wrong position to natural facts in the formation of ethical judgment, to turn ethics into a subdiscipline of biology, and thus to deny what is legitimately called the 'autonomy of ethics"' (2004: 62). We take the value of justice and benevolence to be independent of the evolutionary benefits they may or may not confer. A view that leaves it up to biology to decide what is morally good already fails to capture this second-order moral judgment, and it is hard to imagine it would coincide with our first-order moral judgments about substantial virtues.

This is why neo-Aristotelians do not respond to the Pollyanna Problem by questioning the validity of the empirical research cited but rather by rejecting its relevance to understanding human natural goodness. Two recent advocates of neo-Aristotelian naturalism, Micah Lott (2012b) and John Hacker-Wright (2009) have argued that our understanding of what is naturally good in the life of humans cannot come from empirical science. Lott, who offers a more elaborate argument, appeals to the place of practical reason in human life to make his case. He argues that natural goodness concerns the characteristic way of living and achieving natural ends in a given life-form, and importantly, the human characteristic way of living and achieving natural ends is the way of practical reason. Thus, a proper understanding of human natural goodness involves an understanding of practical reason. But an understanding of practical reason does not come from empirical science. It involves understanding what makes an action rationally justified or unjustified, which is outside the scope of empirical science. Such an understanding belongs to the realm of the practically wise person, i.e., someone with a substantive grasp on reasons and a proper sensitivity to various ends and values. Thus, according to Lott, the empirical findings of 
evolutionary psychology do not give us an account of human natural goodness, and cannot be used to derive conclusions about moral virtue (2012b: 417-418).

This response helps with normative adequacy of human natural goodness. If our conception of what is naturally good in human life is formed through practical reason, the result is likely to be in line with our considered judgment about moral virtues, which is also acquired through practical reason. ${ }^{3}$ But if the neo-Aristotelian account of human natural goodness is informed by an understanding of practical reason, it is no longer obvious that it is a naturalist account. Note that the norms of practical reason aren't any more obviously natural than the norms of moral goodness. Because of this, neo-Aristotelians owe their opponents a defense, or at least a clarification, of their claim to naturalism.

However, Lott does not interpret the Pollyanna problem as a problem for the claim to naturalism. He rather treats it as an epistemological challenge. He tries to show that although empirical science does not give us knowledge of the human life-form, we have other means of acquiring such knowledge. According to Lott, aspects of the human life-form that are not investigated by empirical science can be known through acquiring virtue, supposedly because a virtuous person possesses practical knowledge (see Lott 2012b: 423). However, this focus on epistemology is misguided. The question raised by the Pollyanna Problem is not whether one can have knowledge of what neo-Aristotelians are calling 'natural goodness', but whether the object of such knowledge is an aspect of the natural world. The critics who raise the Pollyanna Problem are not moral skeptics. Of course if the norms of natural goodness in human life are stipulated such that they coincide with moral virtue, the critics would not deny that a virtuous person has knowledge of these norms. ${ }^{4}$ But the question remains whether these norms are natural, especially given that our knowledge of them is not empirical knowledge.

In short, the neo-Aristotelian response to Pollyanna, which involves rejecting the relevance of empirical findings, saves the premise of Normative Adequacy, but falls to establish the premise of Naturalism.

\footnotetext{
3 Note that on the neo-Aristotelian conception of practical reason, rationality and morality are not at odds but on the same footing. Practical reason involves not just self-interested considerations but moral considerations as well.

4 Note that if the critics were moral skeptics, Lott's argument which starts from the assumption that there are in fact virtuous people would not convince them.
} 


\section{Naturalness as Continuity with Nature}

The lesson to draw from the Pollyanna objection is that neo-Aristotelian naturalism cannot be interpreted as deriving moral virtues from a scientific, virtue-neutral, account of human nature. ${ }^{5}$ But if what we take to be naturally good in human life is already informed by an understanding of moral virtue, the question remains why tying moral goodness to natural goodness is supposed to amount to ethical naturalism. Why are the norms of natural goodness in human life considered to be natural in the first place?

Here I want to suggest a strategy for defending the naturalness of human nature that has not been explicitly explored. The idea, which I take to be at the core of Foot's appeal to the concept of natural goodness, is to show that the human life-form and the norms of natural goodness that it underwrites are continuous with the rest of nature. In other words, there is a continuity between natural goodness in human beings and natural goodness in non-human animals and plants, such that if the latter is natural so is the former. I take this to be what Foot has in mind when she suggests that moral evaluations "share a basic logical structure and status" with evaluations of plants and animals (2001: 27). ${ }^{6}$ Thus, the basis for the claim to naturalism is not having a value-neutral conception of human life-form, but rather a continuity between the human life-form and other lifeforms, which are supposedly value-laden in the same way. The norms of natural goodness in human life are natural because they are of the same kind as natural norms in non-human life-forms.

There are two important claims being made here. One says that there is a continuity between natural goodness in humans and natural goodness in non-humans, and the other says that the latter is natural. Integrating these claims into our Simple Argument for Naturalism gives us the following, more refined version.

\footnotetext{
5 See Lott (2012a: 420) for a rejection of a 'two-stage' reading of neo-Aristotelian naturalism.

${ }^{6}$ It's important to note that although there is a logical continuity between the human and non-human case in that they are life-forms and have a natural history, there is also an important difference resulting from the fact that the human lifeform is inter alia characterized by practical reason. Because practical reason has practical authority, it also belongs to the human life-form that its bearers characteristically have a sound grasp on practical reason. Thus, there is an important sense in which knowledge of the human life-form has to 'come from the inside'. As Hacker-Wright (2013) puts it, human natural goodness depends on our "rational self-interpretation" (92). This difference between humans and non-humans raises an important question about whether the noted logical continuity is enough to secure what I have characterized as the premise of Continuity. As Lott (2014) articulates the issue, neo-Aristotelians need to show that their account of practical reason relies on the specifically human life-form and not on some more abstract category like 'person' or 'rational agent'. In order to do this, neo-Aristotelians have to explain in what way other aspects of the human life-form relate to practical reason and play a constitutive role. This is a question that needs to be addressed before the neo-Aristotelian project can fully succeed, but it doesn't directly relate to the evolutionary challenge and I must leave it aside here. See Hacker-Wright (2013) for an attempt to address this question.
} 


\section{Refined Argument for Naturalism:}

1. Norms of natural goodness in non-human life-forms are natural. (Grounding)

2. If norms of natural goodness in non-human life-forms are natural, then norms of natural goodness in the human life-form are also natural. (Continuity)

3. Norms of moral goodness are norms of natural goodness in the human life-form. (Normative Adequacy)

C. Therefore, norms of moral goodness are natural.

Note that the last premise of the argument has not changed. It still involves what I characterized as the premise of Normative Adequacy. We saw that Neo-Aristotelians secure this premise by arguing that knowing what is naturally good in human life involves acquiring moral virtue. But now we have two other premises to worry about. Let's call the first premise Grounding and the second one Continuity.

As it turns out, the two new premises introduce a challenge comparable to the dilemma we faced earlier between Naturalness and Normative Adequacy. The norms of natural goodness in non-human life should be characterized such that they are natural, but also such that they are continuous with the norms of natural goodness in human life-i.e., norms that include moral norms. It seems that a version of the old dilemma has reappeared. We can ensure Grounding by characterizing non-human natural goodness in terms of biological functions or adaptiveness. But there would be a question whether such evolutionary norms can be seen as continuous with the relevant set of norms in human life. On the other hand, we can stipulate norms of natural goodness in non-human life such that Continuity is secured, but it would not be clear whether such stipulated norms are natural.

Interestingly, this brings us to the second version of the evolutionary objection, which primarily focuses on natural goodness in non-human life-forms. Fitzpatrick (2000) offers an evolutionary account of biological function to argue that biological functions do not coincide with an organism's flourishing or welfare. I will argue that this objection should be understood as challenging the premise of Continuity while the premise of Grounding is secured. In the next section, I first present the objection as an instance of the dilemma that forces us to choose between these two premises, and then assess the neo-Aristotelians' response. 


\section{The Selfish Gene Problem}

The objection that I am calling the Selfish Gene Problem is posed as a general problem for the neo-Aristotelian account of natural goodness without particularly focusing on the case of human beings. We saw that Foot characterizes natural goodness in terms of a concept of function that is based on a trait's characteristic contribution to the organism's flourishing, where flourishing is understood in natural-historical terms. On Foot's account, when we say deep roots are naturally good in an oak, we are evaluating the roots in relation to their function in enabling the oak to flourish as an oak, i.e., to live a characteristic oak life. It is this flourishing-based account of function that is the focus of Fitzpatrick's objection. Fitzpatrick's core idea is that we need to view living things in light of their being products of evolution in order to get a grasp on their functional aspects. He gives an evolutionary account of biological function in terms of gene replication, and argues that the neo-Aristotelians' flourishing-based account of function should be rejected. This objection is often taken to be very different from the Pollyanna Problem and attacking natural goodness independently of its relation to moral goodness. But here I argue that it is ultimately raising the same dilemma except at a different level.

Fitzpatrick (2000) appeals to a genocentric understanding of evolution to develop his evolutionary account of biological function. This view of evolution, which Fitzpatrick adopts from philosophers of biology like Dawkins (1983), and Sterelny and Kitcher (1988) puts genes at the centre of the main processes of evolutionary change. Natural selection is seen as resulting from genes increasing their frequency in the gene pool by exerting phenotypic effects in organisms such that these effects ultimately serve to promote the propagation of the genes. Based on this understanding of natural selection, Fitzpatrick argues that the ultimate function that natural selection has devised for organisms and their parts and features is to increase the frequency of their genes. According to Fitzpatrick's account of biological function, for an entity to have a biological function is for it to play a non-accidental role in promoting the "ultimate biological end" of replication of its genes (2000: 103-104).

Fitzpatrick argues that once we understand biological functions in this way, we will see that they do not always promote the welfare of an organism. There is no reason to think that gene replication, which is a blind evolutionary force, always promotes organismic welfare, at least according to our intuitive conception of what an organism's welfare consists in. Fitzpatrick gives examples of traits that are biologically functional for the members of a species but nonetheless do 
not seem to promote their welfare. Male elephant seals, for instance, fight with each other in order to gain exclusive control of females for mating, which sometimes results in their injury or even death. Although these fights are effective in replicating their genes and are thereby in line with thier proper biological functioning, they are not conducive to their welfare-given what we ordinarily think of as well-being for a sentient animal. What Fitzpatrick concludes from his discussion is that the neo-Aristotelian account of function, which he calls a "welfare-based" account, is false (2000: $\S 3)$.

Although Fitzpatrick raises this objection in terms of the concept of welfare, it would be more appropriate to formulate it in terms of the neo-Aristotelian concept of flourishing, which consists in the organism's exemplifying the characteristic life of its life-form. While Fitzpatrick's appeal to "our ordinary, if somewhat fuzzy, conception of organismic welfare" (69) makes it easier to find cases where biological function proves detrimental to welfare, the natural-historical conception of flourishing that is central to the neo-Aristotelian project does not have to square with our intuitions about welfare. ${ }^{7}$ Nonetheless, we can see that Fitzpatrick's criticism of a welfarebased account of function ultimately threatens a flourishing-based account as well. If his conception of biological function is correct, then biological functions do not concern flourishing any more that they concern welfare, even though they may happen to coincide with flourishing in many cases. Unless we define flourishing in ultimately genetic terms, there is no reason to suppose that the functions of gene-replicating entities will necessarily line up with what promotes the organism's flourishing. And of course we cannot define flourishing in genetic terms without violating Continuity. ${ }^{8}$ The concept of flourishing is the basis for evaluations of natural goodness, and we need these evaluations to be continuous across the human and non-human domain. But evaluations of natural goodness in humans are tied with moral virtue, and understanding those in genetic terms would violate Normative Adequacy. This is why neo-Aristotelians define flourishing in terms of natural history and not in relation to gene replication.

The Selfish Gene Problem thus targets the tension between the premises of Continuity and Grounding. If we understand natural goodness in non-humans in terms of biological functions,

\footnotetext{
7 Note, for instance, that it's not at all obvious that the violent fights of elephant seals are detrimental to their flourishing in the sense of living the characteristic life of their life-form.

${ }^{8}$ Fitzpatrick gives the impression that the problem with defining welfare in terms of gene replication is that it would be "a radical departure from intuitive notions of organismic welfare or well-being" (68). But it's important to clarify that it is not our intuitions regarding the flourishing of animals like elephant seals that keep us from defining flourishing in genetic terms. The reason has to do with the requirement of Continuity.
} 
Grounding will be uncontroversially secured. But if, as Fitzpatrick argues, biological functions do not concern any suitable conception of flourishing, then Continuity will be compromised. The structure of the Selfish Gene Problem is therefore similar to the Pollyanna Problem. It relies on a scientific account of natural goodness to question whether it can be tied to flourishing and ultimately moral virtue.

In response to Fitzpatrick's objection, Neo-Aristotelians reject the idea that that their claims about natural goodness have anything to do with Fitzpatrick's biological functions. They argue that they are giving an account of a different type of function that is not supposed to coincide with the type that interests evolutionary biologists. Hacker-Wright (2009) and Lott (2012a) have both responded to Fitzpatrick along these lines, bringing out the fact that Foot herself explicitly says that the type of function she has in mind is distinct from a biological adaptation (see Foot 2001: $32)$.

Lott defends the neo-Aristotelian account of function qua an account of function, arguing that it meets the desiderata of a successful account of function. One of Fitzpatrick's charges against the flourishing-based account is that because it ignores the history of a trait, it cannot make sense of the distinction between a genuine end served by a function and an accidental benefit (see 2000: 185-207). But Lott rightly argues that although the flourishing-based account does not draw this distinction based on evolutionary history, it does draw the distinction on another basis, namely the characteristic life cycle of the life-form (see Lott 2012a: 367-374). In other words, not just anything that contributes to an organism's natural ends is considered functional on the neo-Aristotelian account. A feature or behavior is considered functional if and only if it plays a part in the characteristic life cycle of the organism's life-form.

However, showing that the flourishing-based account gives a conception of function that is distinct from the evolutionary conception of function is not sufficient to solve the Selfish Gene Problem. It only addresses one horn of the dilemma, i.e., the problem of continuity. Surely if natural goodness for plants and animals is characterized in terms of an account of function that is defined based on a suitable conception of flourishing, the continuity across the human and nonhuman natural goodness is preserved. But are these supposedly flourishing-based functions natural? Although Fitzpatrick does not explicitly discuss the premise of Grounding, it is clear that trying to understand natural goodness within a naturalist framework is in the background of his appeal to evolutionary functions. 
What does it take for an account of function to be naturalistic? In the philosophical literature on the concept of function in biology, this is often taken to involve identifying the necessary and sufficient conditions for functional ascription in reductive terms that are uncontroversially natural. ${ }^{9}$ Etiological theories of biological function identify these conditions in terms of the causal history of a trait (see Wright 1973; Millikan 1989; Neander 1991). Fitzpatrick’s account similarly specifies these conditions in reductive causal terms, particularly in terms of contribution to gene replication. ${ }^{10}$ In rejecting the flourishing-based account of function, Fitzpatrick seems to assume that specifying the ascription conditions in reductive terms is required for having a naturalistic account of function. ${ }^{11}$ However, neo-Aristotelians characterize conditions for functional ascription in terms of the concept of flourishing while admitting that what counts as flourishing of an organism or characteristic of its life-form is itself understood in functional terms. ${ }^{12}$ In other words, neo-Aristotelians are aware that they cannot specify the conditions for functional ascription in noncircular reductive terms (see Lott 2012a: 371-372), and yet they take flourishing-based functions to be natural.

But how can neo-Aristotelians argue that their non-reductive account of flourishing-based functions is naturalistic? Note that as long as we are dealing with the premise of Grounding, we are only concerned with the functional aspects of plants and non-human animals, i.e., creatures that we can plausibly take to be part of the natural world. Because of this, the question is not whether the flourishing-based functions in question are natural or non-natural, but whether they exist - independently of us - at all. What threatens the premise of Grounding is not the idea that the flourishing of an oak or flourishing-based functions of its roots are somehow non-natural. It is rather the question of whether, as a matter of fact, the oak has a flourishing to begin with. Thus, arguing that flourishing and flourishing-based functions are natural requires showing that they actually exist in the uncontroversially natural, non-human, domain.

\footnotetext{
9 Regardless of whether or not these accounts are taken to offer a reduction of the concept of function, the conditions they specify for function ascription are reductive in the sense that they can be understood without making any reference to the concept of function.

${ }^{10}$ Note that Fitzpatrick denies that his account of function is a standard etiological theory (229-246).

"Another biologically-inclined critic, Odenbaugh (2015) seems to makes the same assumption when he claims that the etiological account of function is "the only good theory we have of normative natural functions". In fact, he goes as far as claiming that because the neo-Aristotelian account of function is not reducible to our best scientific accounts of functions it is not a naturalistic theory, but a form of vitalism.

${ }^{12}$ Note that an organism's flourishing is given in a system of natural-historical judgments that express the characteristic features that "play a part" in the life of that kind of organism.
} 
It may be thought that the picture neo-Aristotelians draw of the norms of natural goodness in the life of plants and animals is just too plausible to deny. Foot says, for instance, that "nobody would ... take it as other than a plain matter of fact that there is something wrong with the hearing of a gull that cannot distinguish the cry of its own chick, as with the sight of an owl that cannot see in the dark" (2001: 24). However, a critic like Fitzpatrick argues that such appearances are explained away by evolutionary biology, which supposedly reveals that these organisms are nothing but gene-replicating machines without a flourishing characteristic of their life-form. ${ }^{13}$ The upshot of the Selfish Gene objection is that flourishing-based functions have no place in our best account of plants and animals. If this is correct, then even though we sometimes make evaluations of parts and aspects of plants and animals, such evaluations are only correct when they line up with evolutionary adaptations.

In short, the neo-Aristotelian response to the Selfish Gene Problem secures the premise of Continuity by arguing that the flourishing-based conception of function is distinct from the evolutionary conception. But in order to secure the premise of Grounding, neo-Aristotelians need to show that flourishing-based functions are necessary for understanding non-human living things and cannot be dispensed with in light of a scientific account of living things. In the next section, I discuss what I take to be the best strategy for making such an argument.

\section{The Argument from Representation of Life}

How can neo-Aristotelians argue that the flourishing-based conception of function is necessary for understanding plants and animals? Thompson offers a transcendental argument for the life-form concept that has served as the foundation of the neo-Aristotelian account of natural goodness. In his work on representation of life, Thompson argues that the life-form concept, together with its implications of goodness and defect, is necessary for representing a living thing as living. Given that flourishing-based functions are defined in terms of the life-form concept, this transcendental argument is most relevant to the question at hand. If the life-form concept is necessary for understanding living things, so is the flourishing-based conception of function.

\footnotetext{
${ }^{13}$ Another way to explain away the evaluations of natural goodness, particularly in the case of sentient animals, would be to allow that they have a welfare, but only one that is entirely rooted in their desires and their ability to feel pleasure and pain. Note that this concept of welfare doesn't depend on an organism's life-form, but is rather based on the individual's own psychology. So it is different from the neo-Aristotelian concept of flourishing and thus is not suitable for offering a naturalist account of moral virtue.
} 
Thompson argues that apprehending something as living requires viewing some of its parts as organs like legs and wings, and some of its activities and processes as vital operations like eating and breathing. But what counts as a leg or what counts as eating differs from one kind of organism to another. In fact, the same physical entity or process can amount to different organs or vital operations in different life-forms. For instance, the process of cell division amounts to reproduction in bacteria but constitutes growth in humans. According to Thompson, there is nothing "in the organism considered in its particularity or as occupying a certain region of space" which determines that an organ is there or a vital operation is happening. "That they are there or happening, and thus that we have an organism at all, presupposes the existence of a certain 'wider context"', which Thompson takes to be the context of a life-form concept (2008: 56). Thus, he argues that apprehending something as living requires presupposing a life-form concept and its corresponding natural history. Moreover, a life-form concept brings with it not just the context required for recognizing organs and operations, but also the related norms of natural goodness and flourishing-based function. For instance, when we recognize an individual living thing as a bat, we already commit ourselves to assessing it against the norms that are implicit in our conception of the bat life-form. No doubt, our conception might be incomplete and some of the naturalhistorical judgments that we make may be false. We may initially make the natural-historical judgment that "bats are blind" but later find out that "bats can see". But according to Thompson, however we may revise our conception, it remains the case that presupposing some conception of the life-form and taking some natural-historical judgments to be true is necessary for identifying the bat as a living organism. Thus, to the extent that we do represent and identify living things as living, we are committed to there being norms of natural goodness and flourishing-based function that apply to them.

The problem with this argument is that, much like Foot's intuitively plausible remarks, it relies on commonsense descriptions of living things rather than state-of-the-art science. Thompson may be right that we ordinarily make natural-historical judgments when we apprehend living things. But it is not clear that the framework of natural-historical judgments and the concept of life-form that they underwrite provide the best conceptual tool for understanding the objects we perceive. Thompson allows that we may revise our conception of a life-form in light of empirical 
observations. ${ }^{14}$ But he takes the logical structure of our representations - the special logical form of natural-historical judgments - to remain intact. In other words, he thinks what a characteristic bat life consists in is subject to revision, but that there is a characteristic bat life that is expressible in the form of natural-historical judgments is not. However, it's not clear why this aspect of our folk understanding of living things cannot be empirically questioned. Why should we assume that individual bats are best understood in relation to characteristic norms that group them together? Thompson draws on the fact that the logical form of natural-historical judgments is distinct from other forms of generality, and that we seem to use these judgments exclusively in relation to living things. Yet, this is not enough to show that we can take any aspect of these judgments for granted. Science often dispenses with our folk understanding of things by offering theories that are superior and explain the relevant phenomena better. This is clear in the case of modern physics, which has replaced our naïve conception of the physical world. There is an extensive literature on our intuitive explanations of motion that suggests they are fundamentally different from Newtonian explanations (Nersessian and Resnick 1989; McCloskey 1983). We seem to commonly apply a model resembling Aristotelian physics, according to which continuous motion requires the sustained force of an internal or external cause, unlike the state of rest, which doesn't require any causal explanation. In contrast, Newtonian physics maintains that a moving object continues to move until acted upon by some external force. It contradicts the commonsense intuition by suggesting that motion is a state and only changes of state (e.g., accelerated motion) require explanation. The folk view may work fine when we do not need to make accurate predictions, but it loses ground to modern science when prediction and accuracy become important. The naturalhistorical conceptual framework similarly belongs to our folk understanding of the world and could be replaced by mature scientific theories, which is what the Selfish Gene Objection suggests.

That being said, if it turns out that the representation of living things in modern biology also presupposes the life-form concept, then the argument from representation of life will have some teeth. In fact, Lott and Hacker-Wright have both tried to make such an argument, claiming that even a science like evolutionary biology has to presuppose the life-form concept. As I will argue below, however, their defense of this claim does not add much to Thompson's transcendental argument. There are two considerations that they offer to defend the claim that evolutionary

14 See Thompson's (2004) vivid discussion of how empirical observations guide us in acquiring knowledge of a novel type of jellyfish. 
biology presupposes the life-form concept. The first is that living things are the subject matter of evolutionary biology. The second is that some of the explanatory concepts of evolutionary biology presuppose the life-form concept. Let's call these the argument from subject matter and the argument from explanatory role. In the remainder of this section I examine these arguments in turn.

The argument from subject matter appeals to the fact that biology is the study of living things. Lott and Hacker-Wright argue that since biology is about living things, biologists are already committed to the life-form concept that is involved in recognizing living things in the first place. Lott says, for instance, that "to so much as have a topic for evolutionary explanation, we must rely on Thompson-Foot judgments of life form" (2012a: 375). Hacker-Wright similarly claims that a life-form conception "is always in play when we make a judgment of an organism," regardless of whether we are doing armchair speculation or evolutionary biology. (2009: 316).

However, this argument is far too quick. Our initial characterization of the subject matter of a science is merely a starting point. The question is whether the ultimate scientific account of the subject matter under study remains faithful to our initial characterization. Take organic chemistry - the study of organic compounds, which were initially taken to be compounds found in living organisms. The division between organic and inorganic chemistry was motivated by the fact that compounds derived from plants and animal sources seemed to have distinctive features such as being less stable and more prone to decomposition. These differences were thought to be explained by the vital force theory, the idea that a vital force existed within organic material. However, it turned out that the very compounds that were the focus of organic chemistry were also obtainable from non-living sources. Organic compounds were thus redefined as compounds that contain a significant amount of carbon, even those with a non-biological origin. ${ }^{15}$ Consequently, modern organic chemistry does not support the vital force theory or any other theory regarding what makes living things distinctive. As far as organic chemistry is concerned there is no distinction between living and non-living things.

Thus, the mere consideration that the subject matter of evolutionary biology is prescientifically characterized in natural-historical terms does not lend any support to the life-form concept. It is not at all obvious that the scientific account of this subject matter is best characterized

15 See Klein (2005) for an account of the shifting ontology of chemistry in the $18^{\text {th }}$ and $19^{\text {th }}$ century. 
in a way that presupposes the life-form concept. In fact, the Modern Synthesis theory of evolution, which is at the core of Fitzpatrick and Dawkins' genocentrism, does not characterize evolution in terms of living organisms at all. It rather defines evolution as change in gene frequencies within a population of genes over time (see Dobzhansky 1973: 12). Thus, as many historians and philosophers of biology have noted, there is a shift in the subject of evolutionary explanation and the ontology of biology from organisms in Darwin's theory to genes and populations in Modern Synthesis. ${ }^{16}$

One may think the concept of a gene itself somehow presupposes the concept of an organism, which in turn presupposes a life-form concept. This brings us to the second argument found in Lott and Hacker-Wright's remarks, namely that some of the explanatory concepts of evolutionary biology rely on the life-form concept. More specifically, Lott suggests that representing something as a gene, or an activity as reproducing, requires the context of a life-form in the same way that representing something as an organ or as a vital operation does (2012a: 375). ${ }^{17}$ If this is correct, not only does evolutionary biology focus on a subject matter that is initially characterized by appeal to life-forms, its theoretical account and explanation of this subject matter is also committed to the life-form concept.

If successful, the argument from explanatory role shows that life-forms are explanatorily indispensable to evolutionary biology, and therefore, that evolutionary biology vindicates the natural-historical conceptual framework. However, the central premise in this argument is that the conception of gene or reproduction in evolutionary biology presupposes the life-form concept, and this is not sufficiently argued for. Lott's idea seems to be that the life-form concept must be in the background of evolutionary concepts for the same reason that it is in the background of everyday descriptions of living things — namely that natural-historical judgments are involved in identifying the domain of life. But note that the conception of gene in evolutionary theory does not have to be the same as the folk conception of gene. Although the folk conception may presuppose the lifeform concept, it's not clear that the scientific conception of gene has any such presuppositions. If it turns out, for instance, that evolutionary biology defines genes in molecular terms by reference to their replicability and their immediate function in protein construction, no reference to the lifeform of the organism seems necessary. Thus, insofar as Lott and Hacker-Wright assume that the

\footnotetext{
${ }^{16}$ See Daniel Nicholson's remarks on the disappearance of the organism in evolutionary theory (Nicholson 2014, 1-2).

${ }^{17}$ Hacker-Wright made similar remarks about the concept of gene in personal communication.
} 
scientific conception of gene must be the same as the folk conception, or that it must somehow presuppose the life-form concept simply because it concerns the domain of life, their argument from explanatory role does not add much to their argument from subject matter.

What is missing in Lott and Hacker-Wright's argument is looking at the conception of gene in evolutionary biology and asking whether its explanatory role requires presupposing the lifeform concept. This is not at all a trivial question, and it is not my aim here to argue against it. I am merely arguing that the issue is not to be decided a priori without consulting evolutionary biology. At least prima facie, Modern Synthesis biology does not characterize genes by reference to organisms, let alone life-forms. It is rather organisms that are characterized in terms of genes. As Dawkins' (1976) description illustrates, organisms are taken to be nothing but "survival machines - robot vehicles blindly programmed to preserve the selfish molecules known as genes" (xxi). Thus, it is not immediately obvious that the life-form concept plays any explanatory role in Modern Synthesis evolutionary biology.

Neo-Aristotelians may respond that if Dawkins' reductive account is an accurate portrayal of evolutionary biology, it just shows that evolutionary biology is not relevant to the study of living things as living. Evolutionary biology has very specific explanatory aims and it may turn out that it doesn't need to take account of all aspects of living things to meet these specific aims. Just as the lack of a distinction between living and non-living things in organic chemistry doesn't refute Thompson's account, the reductionism of evolutionary biology doesn't have to threaten this account either. Thus, neo-Aristotelians may drop the argument from explanatory role but insist that any relevant field of science that studies the realm of living things as living would inevitably depend on the natural-historical framework.

However, this is again a claim that begs the question against the critic. It's true that no branch of science captures all aspects of reality. But this doesn't make folk biology and the naturalhistorical framework that it underwrites immune to refutation from empirical sciences. Although it may be argued that there are aspects of reality that are not knowable via the methodology of empirical science, there is no reason to think that the domain of life is one of them, particularly when it comes to plants and non-human animals. Note that folk biology does not have any privileged position with respect to accounting for what makes living things distinctive. Naturalhistorical judgments are not any more geared toward representing living things as living than are 
the claims of evolutionary biology. ${ }^{18}$ The only difference is that the latter have superior epistemological credentials due to the systematic rigor of scientific practice. Thus, even if one is to argue that Dawkins' reductive account fails to capture parts of reality, such an argument needs to be made either by appeal to other branches of biological science such as ecology or ethology, or based on considerations internal to evolutionary biology itself.

Moreover, even if it turns out that the implicit presuppositions of evolutionary biology or other biological sciences favor a non-reductive account of the organism, it doesn't immediately follow that the natural-historical conceptual framework is vindicated-just as it doesn't follow that the vital force theory is vindicated. Thompson's natural-historical account is just one non-reductive theory of the organism. If we find that biological sciences are implicitly committed to some irreducible conception of the organism as an entity that is explanatorily prior to its genes, there is a further question what this conception consists in and whether it lends any support to Thompson's theory in particular.

To sum up, the best strategy for securing the premise of Grounding is to argue that the lifeform concept plays an indispensable explanatory role in a biological science. But the first step in making such an argument is acknowledging that the content of empirical science is relevant to answering this question. Such an argument cannot assume that any aspect of our folk biology is immune to refutation. Thus, taking the content of empirical science seriously means being willing to defer to a scientific account of the organism, even if it potentially results in a revision of the natural-historical picture.

\section{Making Peace with the Relevance of Empirical Science}

Neo-Aristotelians have kept their account of natural goodness at a safe distance from the science of biology, and even when they make claims about the presuppositions of evolutionary biology, they treat the question as an a priori matter. In this final section, I discuss some of the reasons neoAristotelians might think they should keep biology at arm's length, and offer some thoughts to counter these reasons.

The most obvious reason for neo-Aristotelians to avoid engaging with evolutionary biology would be assuming that the science is not on their side. Critics of neo-Aristotelian naturalism

\footnotetext{
${ }^{18}$ When we make a judgment like "cats have four legs" we aren't primarily concerned with identifying what makes cats living but are simply trying to understand the kind of thing in front of us.
} 
appeal to a genocentric, arguably reductionist, account of evolution that has been very influential in philosophy of biology since the rise of Modern Synthesis in the twentieth century. If this account of evolution is accurate, the prospects of arguing for a suitable account of natural goodness by consulting evolutionary biology would be dim. As I mentioned earlier, the concept of an organism as an irreducible entity does not seem to have a place in Modern Synthesis. Genes are seen as the sole units of inheritance and selection, and even the organismic process of development is considered to be a mere execution of a genetic program (see e.g., Williams 1966; Monod 1971).

However, what both neo-Aristotelians and their critics seem to overlook is that Modern Synthesis has been seriously challenged from various fronts in recent years. Empirical advances in the understanding of development (Oyama 2000; Oyama, Griffiths, and Gray 2001), evolutionary novelty and selection (West-Eberhard 2003; 2005), and epigenetic inheritance mechanisms (Jablonka and Lamb 1995; 2005) have revealed many theoretical shortcomings of the genocentric approach. Some biologists and philosophers of biology have called for "the return of the organism" (Nicholson 2014), suggesting a very different view of evolution. On this organocentric view, organisms are the primary agents of evolutionary change, and the main processes of evolution are consequences of the distinctive capacities of whole organisms such as their plasticity and robustness (see Walsh 2016; Pigliucci and Müller 2010; Huneman 2010). This alternative approach to understanding evolution lends itself well to a neo-Aristotelian argument for a holistic concept of organism. Of course, effectively making such an argument requires a good examination of the relevant work in evolutionary developmental biology. ${ }^{19}$ Moreover, as I pointed out earlier, there would be a further question what this holistic conception of the organism consists in and whether Thompson's natural-historical account does justice to it. But there is reason to think that the most empirically adequate account of evolution and development may in fact yield a conception of organism that can lead to a suitable account of natural goodness.

One may object that there is a more principled reason against relying on the science of biology that has to do with autonomy of ethics. On the neo-Aristotelian view, the concept of a living organism is the basis for all evaluations of natural goodness including evaluations of moral goodness in humans. The concern is that by making the appropriate concept of organism contingent upon the facts of biology, the kind of necessity that is appropriate to moral goodness

\footnotetext{
19 See, e.g., how Laubichler and Wagner (2000) argue that taking the concept of organism to be ontologically prior to its functional structures can solve certain problems of mathematical models in biology with character identification.
} 
will be lost. In other words, even if biologists and philosophers of biology were to decide that the neo-Aristotelian life-form concept is necessary for explaining biological facts, the mere possibility that empirical findings could reveal things to be otherwise seems damaging to the autonomy of ethics. As Thompson might say, consulting biology to answer the question would be giving a wrong position to biological facts and turning ethics into a sub-discipline of biology.

However, my suggestion here is not that we should consult biology for an account of what flourishing and moral goodness in humans consists in. The question is whether the concept of organism that yields the best understanding of living things - including plants and non-human animals - is suitable for grounding the norms of flourishing and moral goodness in humans. What I am suggesting is that biology is the relevant filed to look for the appropriate concept of organism. If biology shows that our most empirically adequate concept of organism is not suitable for grounding the norms of natural goodness, it is not our conception of human goodness, but the continuity between humans and non-humans that faces a challenge. Thus, the kind of relationship with science that I am advocating does not threaten the autonomy of ethics. We do not look to justify our substantial moral virtues like justice and benevolence 'from outside' via virtue-neutral biological facts. It is part of the neo-Aristotelian account of virtue that the justification for substantial virtues comes from practical reason and not through biology. It is rather the justification for the neo-Aristotelian metaethical position of naturalism that has to come in part from biological facts, which is not surprising given that it is a naturalist position with commitments about biological entities.

In summary, I have argued that the evolutionary objection to neo-Aristotelian naturalism ultimately raises a question of naturalistic credentials for this view. As a naturalist account of virtue that relies on there being a continuity between humans and non-humans, neo-Aristotelian naturalism has a set of commitments about the life of plants and non-human animals that are best investigated by empirical science. I have argued that the reason the current responses to both versions of the evolutionary objection fail is that neo-Aristotelians distance their view from empirical science in a way that is unnecessary and unjustified. Thus, in order to move forward in this debate, I propose that neo-Aristotelian naturalism should own its empirical commitments and rethink its relationship with biology. 


\section{References}

Andreou, C. (2006). Getting on in a varied world. Social Theory and Practice, 32(1), 61-73.

Dawkins, R. (1976). The selfish gene. New York: Oxford University Press.

Dawkins, R. (1983). The extended phenotype: the long reach of the gene. New York: Oxford University Press.

Dobzhansky, T. (1937). Genetics and the origin of species. New York: Columbia University Press.

Fitzpatrick, W. J. (2000). Teleology and the norms of nature. New York: Garland Pub.

Foot, P. (2001). Natural goodness. Oxford: Clarendon.

Frank, R. H. (1985). Choosing the right pond: human behavior and the quest for status. Oxford [Oxfordshire]: Oxford University Press.

Hacker-Wright, J. (2009). What is natural about Foot's ethical naturalism? Ratio, 22(3), 308321.

Hacker-Wright, J. (2013). Human nature, virtue, and rationality. In J. Peters (Ed.), Aristotelian ethics in contemporary perspective (pp. 83-96).

Hirshleifer, D., \& Rasmusen, E. (1989). Cooperation in a repeated prisoners' dilemma with ostracism. Journal of Economic Behavior and Organization, 12(1), 87-106.

Hrdy, S. B. (1999). Mother nature: a history of mothers, infants, and natural selection. New York: Pantheon Books.

Huneman, P. (2010). Assessing the Prospects for a Return of Organisms in Evolutionary Biology. History and Philosophy of the Life Sciences, 32(2/3), 341-371.

Hursthouse, R. (1999). On virtue ethics. New York: Oxford University Press.

Jablonka, E. (1995). Epigenetic inheritance and evolution : the Lamarckian dimension. New York: Oxford University Press. 
Jablonka, E. (2005). Evolution in four dimensions : genetic, epigenetic, behavioral, and symbolic variation in the history of life. Cambridge, Mass.: MIT Press.

Kitcher, P., \& Vickers, L. A. (2003). Pop socio-biology reborn: The evolutionary psychology of rape and violence. In P. Kitcher (Ed.), In Mendel's mirror: philosophical reflections on biology (pp. 333-355). Oxford: Oxford University Press.

Klein, U. (2005). Shifting ontologies, changing classifications: plant materials from 1700 to 1830. Studies in History and Philosophy of Science Part A, 36(2), 261-329.

Laubichler, M. D., \& Wagner, G. P. (2000). Organism and character decomposition: Steps towards an integrative theory of biology. Philosophy of Science, 67, 289-300.

Lloyd, E. A. (2001). Science gone astray: evolution and rape. Michigan Law Review, 99(6), 1536-1559.

Lott, M. (2012a). Have Elephant Seals Refuted Aristotle? Nature, Function, and Moral Goodness. Journal of Moral Philosophy, 9(3), 353-375.

Lott, M. (2012b). Moral virtue as knowledge of human form. Social Theory and Practice, 38(3), 407-431.

Lott, M. (2014). Why be a good human being? Natural goodness, reason, and the authority of human nature. Philosophia, 42(3), 761-777.

McCloskey, M. (1983). Naive theories of motion. In D. Gentner \& A. L. Stevens (Eds.), Mental models (pp. 299-324). Hillsdale, N.J.: L. Erlbaum Associates.

Millgram, E. (2009). Life and action. Analysis, 69(3), 557-564.

Millikan, R. G. (1989). In Defense of Proper Functions. Philosophy of Science, 56(June), 288302.

Monod, J. (1971). Chance and necessity: an essay on the natural philosophy of modern biology. (A. Wainhouse, Trans.). New York: Knopf.

Neander, K. (1991). Functions as selected effects: the conceptual analyst's defense. Philosophy of Science, 58(2), 168-184. 
Nersessian, N. J., \& Resnick, L. B. (1989). Comparing historical and intuitive explanations of motion: Does naive physics have a structure. In Proceedings of the 11th Annual Conference Cognitive Science Society. Psychology Press.

Nicholson, D. J. (2014). The return of the organism as a fundamental explanatory concept in biology. Philosophy Compass, 9(5), 347-359.

Odenbaugh, J. (2015). Nothing in ethics makes sense except in the light of evolution? Natural goodness, normativity, and naturalism. Synthese, 1-25, doi:10.1007/s11229-015-0675-7.

Oyama, S. (2000). The ontogeny of information. Durham, N.C.: Duke University Press.

Oyama, S., Griffiths, P. E., \& Gray, R. D. (Eds.). (2001). Cycles of contingency: developmental systems and evolution. Cambridge, Mass: MIT Press.

Pigliucci, M., \& Müller, G. B. (Eds.). (2010). Evolution, the extended synthesis. Cambridge, MA: MIT Press.

Sterelny, K., \& Kitcher, P. (1988). The return of the gene. The Journal of Philosophy, 85(7), 339-361.

Thompson, M. (2004). Apprehending human form. Royal Institute of Philosophy Supplement, $54,47-74$.

Thompson, M. (2008). Life and action: elementary structures of practice and practical thought. Harvard University Press.

Thornhill, R., \& Palmer, C. T. (2000). A natural history of rape: biological bases of sexual coercion. Cambridge, Mass.: MIT Press.

Travis, C. B. (Ed.). (2003). Evolution, gender, and rape. Cambridge, Mass.: MIT Press.

Walsh, D. M. (2015). Organisms, agency, and evolution. Cambridge: Cambridge University Press.

West-Eberhard, M. J. (2003). Developmental plasticity and evolution. New York: Oxford University Press. 
West-Eberhard, M. J. (2005). Phenotypic accommodation: adaptive innovation due to developmental plasticity. Journal of Experimental Zoology (Mole Dev Evo), 304B(6), 610618.

Williams, G. C. (1966). Adaptation and natural selection. Princeton, N.J: Princeton University Press.

Wilson, D. S., \& Dugatkin, L. A. (1997). Group selection and assortative interactions. The American Naturalist, 149(2), 336-351.

Woodcock, S. (2006). Philippa Foot's virtue ethics has an Achilles' heel. Dialogue, 45(3), 445468.

Wright, L. (1973). Functions. Philosophical Review, 82(2), 139-168. 